those without wide clinical and in particular human experience. The index has the air of having been compiled from the print without insight into the use to be made of it, as the indication opposite 'auto-immune disease' suggests.

The sub-title perhaps gives a fairer picture of the scope of the book. In this narrower orbit, the book is full of a wide variety of illustrative material, much of it new and unexpectedly fresh to a reader who has studied mainly human pathology, and there is no doubt that no one can read the book without learning a great deal; there are some points with which the reviewer would differ: the new tissue in amino-nitrile poisoning outside the bone is new bone, not fibrous, and (from the comparative angle) it is interesting that it happens much less readily in the mouse than in the rat; 'demineralisation' is a dangerous term to use in bone disease; the explanation of 'teratoma' as 'monstrous tumour' is obscure and open to misinterpretation. There is also some doubt whether the relatively complex treatment and wide previous knowledge of human clinical conditions presumed in the reader will not prove too much for the 'students of zoology and related subjects' who are invited on the dust-cover to make use of the book. There is room for an introduction to the general biological problem of disease suitable for all biologists, and in spite of these minor points of criticism and perhaps of an over-polished and expensive production, this volume goes a long way to providing it. It is not the definitive text-book on the subject that we may hope the authors will come to provide, but it is an introductory essay that can be read with pleasure and profit. The stimulus to wider study which is provided by the mention of the rare and curious is of as much value as the reminder that pathology like some other sciences has been too long centred on the human animal.

JOHN W. LANDELLS
PRACTICAL CLINICAL BIOCHEMISTRY, 3rd ed. By Harola Varley. (Pp. viii $+689 ; 83$ figures; 31 tables. 50s London: William Heinemann. 1962.

This is the third edition of a valuable collection of methods In a subsequent edition more emphasis might be laid of the control of accuracy and some recommendations might be varied: for example, permitted variations in the results on a control specimen are not best stated as $q$ percentage of the result. Another matter to which rif attention has been paid is the introduction of automation into the chemical pathological laboratory. There is little or no mention of the use of automatic devices in the laboratory. There are some names which are still mis-speto as they were in the first and second editions. In spite of these criticisms the methods are well described and the book is a necessity for any laboratory carrying oưt chemical pathological determinations.

Blood volume dynamics By H. A. Davis. (Pp. xiii $\frac{+}{t}$ 146; 56 tables; 3 figures. \$7.00.) Springfield Illinois Charles C. Thomas. 1962.

This book has the subtitle 'Studies in Surgical Disease'? It consists of a review of the blood volume (especially in relation to height and weight) and of the regulation and the effects of variations of the blood volume. This is followed by a consideration of blood volume changes in a number of surgical conditions and concludes with useful details of methods. The chief value of the book lies in the record of findings, both by the author and bo other workers; there is not much attempt to refer observao tions back to basic physiology. Nevertheless, bloof volume changes are more important than is general realized, especially in relation to water and electrolyt disturbances, and there must be few clinical pathologis? and surgeons who would not benefit by carefully reading this book.

\title{
The College of Pathologists
}

EXEMPTION FROM PRIMARY EXAMINATION Applications for exemption will not be considered after 31 December 1964.

FOUNDER MEMBERSHIP AND FOUNDER FELLOWSHIP Admission to Founder Membership and Founder Fellowship will cease on 12 July 1964. Those holding consultant appointments in pathology, or appointments of similar status, should apply as soon as possible to the Registrar.

MEMBERSHIP WITHOUT EXAMINATION Applications from medically qualified pathologists attaining consultant status or its equivalent will continue to be considered until 25 April 1966.
FINAL EXAMINATION The first final examination will be held during October/November 1964. Two three-hou written papers will be held on Wednesday 7 October and the practical examinations will be held during the firs half of November.

The closing date for entry to this examination will bf 31 August 1964.

Application forms for the above should be obtained from the Registrar, The College of Pathologists, 12 Grosvenco Crescent, London S.W.1.

T. CRAWFORD, Registrar. 